\title{
A Problemática do Trauma ou o Trauma como um Problema em Psicanálise
}

\author{
Luiz Paulo Leitão Martins* (D) \\ Universidade de Paris, Paris, França
}

\begin{abstract}
RESUMO - Este artigo investiga a noção de trauma em psicanálise. Inicialmente, aborda o trauma a partir da elaboração do conceito de inconsciente, observando como a correlação entre trauma e inconsciente em Freud remete o discurso psicanalítico a um pensamento da finitude. Depois, reenvia esse enunciado para a sua condição histórica: a construção dessas noções aparece como resposta a um problema específico da modernidade colocado pelos acontecimentos da vida, do trabalho e da linguagem. Sob esse prisma, o traumático surge como figura de uma história de problemas, em que a relação entre pensamento e acontecimento precipita no discurso a diferença.
\end{abstract}

PALAVRAS-CHAVE: trauma psíquico, psicanálise, discurso

\section{The Problematics of Trauma or the Trauma as a Problem in Psychoanalysis}

\begin{abstract}
This study investigates the notion of trauma in psychoanalysis. First, it discusses trauma from the elaboration of the concept of the unconscious, showing how the relation between trauma and the unconscious in Freud refers the psychoanalytic discourse to a thought of finitude. Secondly, it sends that statement back to its historical condition: the construction of such notions appears as a response to a specific problem of modernity that comes from the events of life, work and language. In this light, the traumatic emerges as a figure of a history of problems, where the relation between thought and event brings the difference to the discourse.
\end{abstract}

KEYWORDS: psychic trauma, psychoanalysis, discourse

A relação entre psicanálise e contemporaneidade é uma agenda cada vez mais presente no discurso psicanalítico. Os desafios que um tal momento histórico impõe a pesquisadores e clínicos em geral demonstram não só a existência de uma rede complexa de problemas, mas também uma série de tentativas e esboços de respostas dados no interior do próprio campo psicanalítico. Em outros termos, percebe-se de forma cada vez mais presente nos estudos em psicanálise sobre a contemporaneidade a introdução de problemáticas novas, isto é, problemáticas antes se não inexistentes ao menos pouco frequentes no campo psicanalítico, o que deve apontar para um novo espaço de construção de problemas e de soluções no campo de pesquisa em psicanálise.

Ora, se, por um lado, pode-se constatar a introdução de novos problemas sob o aspecto da produção interna em psicanálise - ou seja, na tentativa que se faz nela de acompanhar as principais transformações do contemporâneo e o deslocamento tanto da sintomatologia quanto da demanda de análise no espaço da clínica -, por outro lado, observa-se também toda uma produção crítica sendo realizada pelos mais diferentes saberes a que a psicanálise é submetida. Pode-se mencionar aqui, a título de exemplo, as produções advindas do campo das teorias sociais, em especial aquela das teorias de gênero, quando se coloca em questão o modelo de Édipo como chave interpretativa para a formação do desejo e para os mecanismos de exercício da sexualidade. Assim, vê-se como se torna evidente o semblante problemático do discurso psicanalítico na contemporaneidade, de modo que faz parte da agenda mesma desse discurso a convocação de clínicos e pesquisadores em psicanálise no sentido de retomar o contemporâneo como modos operandi efetivo de atuação e reflexão de um campo

*E-mail: lplmartins@gmail.com

- Submetido: 25/08/2014; Revisado: 26/06/2015; Aceito: 04/08/2015. 
na atualidade. Para dizer de outro modo, torna-se necessário pensar a própria psicanálise enquanto discurso e prática à luz dos acontecimentos do presente, para usar uma expressão própria de Michel Foucault (1984a/1994, pp. 680-681), uma vez que são esses mesmos acontecimentos que nos introduzem em problemáticas novas de investigação e de pesquisa na teoria e na clínica.

Ora, pensar o contemporâneo em psicanálise é pensar a agenda da contemporaneidade em relação à psicanálise: como o presente se transformou? Em que nos tornamos? Como a psicanálise pode tecer uma leitura, uma interpretação disso? Como ela pode atuar e investir sua intervenção? Inversamente, pensar a psicanálise na contemporaneidade é pensar a agenda de pesquisa em psicanálise, levando em consideração a possibilidade de transformação de conceitos e a necessidade de dispor de novos instrumentos face às formas atuais de subjetivação e de produção do mal-estar. Pensar esses deslocamentos, bem como dar indícios de outra possibilidade de afirmação do discurso psicanalítico, consiste em nosso objetivo secundário.

Em que consiste, afinal, nosso objetivo primário com este texto? Vemos que a problemática que gostaríamos de lançar toca a relação entre psicanálise e contemporaneidade, vemos também que o ponto comum que visita ambos os pólos dessa relação, com efeito, é o ponto em que se coloca a questão do presente, das transformações e das rupturas desse presente. Ora, se a contemporaneidade se constitui como momento de ruptura em relação à modernidade, por exemplo, época de surgimento e de consolidação do discurso de Freud, certamente a psicanálise no presente, aquela que vemos se produzir e se inventar a cada vez, deve se colocar numa certa descontinuidade em relação àquela de Freud; talvez seja necessário que se introduza por um outro plano conceitual o acontecimento central do inconsciente no campo da psicanálise. A problemática secundária que apresentamos sugere, portanto, a disposição histórica a partir da qual surge a nossa problemática central: gostaríamos de analisar, estudar o surgimento e os destinos do conceito de inconsciente como trauma em psicanálise.

Num primeiro momento, queremos retomar o conceito de trauma na obra de Freud, retomar o modo de construção e de elaboração desse conceito pelo autor, bem como o seu destino no corpus teórico psicanalítico. Num segundo momento, intentaremos pensar o lugar dessa construção conceitual no plano de transformações do pensamento, entrevisto por uma análise do presente. Esse segundo momento quer tratar o processo de construção em Freud, o processo de produção de enunciados e de conceitos no campo de pesquisa em psicanálise, como estando imerso em um espaço de formação de discursos que constitui seu plano histórico de possibilidade. A expressão e a construção de conceitos em Freud devem obedecer a uma certa regularidade de regras, bem como a uma gramática de formação da arqueologia e da genealogia, em que se produz a modernidade ocidental. Queremos pensar a hipótese do trauma em psicanálise no interior de um campo histórico a que corresponde a configuração específica do pensamento moderno, configuração que é condição de possibilidade de discursos e de relações específicas entre as palavras e as coisas. Assim, ao final do texto, buscaremos indicar o possível desdobramento de um problema que começa na elaboração de Freud e que se dá em correlação com elementos centrais do pensamento moderno para o momento atual de pesquisa e de investigação em psicanálise, em que surgem novas correlações e novas questões às quais a arqueologia e a genealogia da história podem se dirigir.

Antes, no entanto, de analisar o curso dessas transformações, o aparecimento desse conceito, com suas inquietações, reformulações e novas problematizações, queremos fazer uma breve explanação sobre o que é entender o trauma em psicanálise no interior de uma história de problemas. Se o trauma surge para a psicanálise como um problema, é preciso analisar por que motivo ele passou a se constituir como tal, bem como quais foram as diferentes formas e alternativas de solução e de intervenção dadas em função desse acontecimento na modernidade. Essa introdução deve servir não só para expressar a teoria a partir da qual abordamos o trauma, mas para falar de nossa posição ao considerar a presença da noção de trauma em psicanálise como um problema.

\section{PROBLEMATIZAÇÃO DA HISTÓRIA OU A HISTÓRIA COMO HISTÓRIA DE PROBLEMAS}

O problema do trauma, ou melhor, o trauma como um problema - é por essa via que pretendemos oferecer alguma contribuição no que diz respeito à discussão que se fez historicamente e que se faz ainda na atualidade sobre o traumático em psicanálise. Ora, mas o que isso quer dizer? De fato, pensar o trauma como um problema é pensar a introdução dessa noção, ou do conceito que carrega essa noção, no discurso psicanalítico em função de alguns acontecimentos da história. Nossa hipótese é que alguns acontecimentos são responsáveis por promover uma passagem entre elementos do que se poderia chamar de campo não problemático do pensamento para um campo problemático.

De um momento para outro, um acontecimento produziu uma crise de evidências e a noção de trauma passou a ser um problema para a psicanálise. Nossa investigação se interroga sobre o modo pelo qual o trauma se constituiu como problema e analisa algumas formas de solução e de 
respostas que o discurso psicanalítico e a modernidade puderam encaminhar. É somente explicitando o que queremos dizer quando pensamos essa passagem em termos de acontecimento que as noções de problema e de solução ou de resposta podem ser devidamente abordadas, ambas referidas a um processo de problematização na história (Foucault, 1984b/1994, pp. 597-599).

Quando falamos de acontecimento queremos nos referir a alguma coisa que surge como abertura e descontinuidade no espaço da história, alguma coisa que interrompe o curso natural, a disposição necessária dos enunciados e dos discursos. Ora, essa abertura é o que permite o aparecimento do que é necessariamente contingente na história (Foucault, 1971/1994, pp. 136, 140, 148): é que surge algo novo no pensamento, algo raro, inédito, imprevisto, de modo que sua presentificação, antes de ser antecipada ou antecipável, é acima de tudo acaso e novidade. A relação entre história do pensamento e abertura do acontecimento não implica necessariamente a ideia de um progresso ou mesmo de uma evolução valorada ou não positivamente no percurso do pensamento. O que está em jogo, e essa é uma hipótese fundamental do pensamento de Foucault, é que o pensamento é formado por blocos de possibilidade contínua, aquilo a que a arqueologia denomina de períodos de longa duração, mas também de momentos de descontinuidade e ruptura. Tais irrupções acontecimentais, para usar um termo desse mesmo autor, são capazes de formar na arqueologia do saber o que se poderia chamar de genealogia da história (Foucault, 1980/1994, p. 28).

Mas a dúvida ainda permanece: o que esses acontecimentos produzem no pensamento? O que a irrupção de acontecimentos desse tipo promove na história do pensar? Resposta: problemas! Tudo se passa como se a produção de acontecimentos, a incursão de acontecimentos na história, produzisse nessa mesma história uma crise de evidências: é que o acontecimento parece produzir um abalo no conjunto daquilo que se mostra como necessário em um dado período, afirmando que talvez essa necessidade não seja tão natural assim, afirmando talvez a possibilidade de uma outra configuração, outra disposição de um mundo possível. Existem outras respostas possíveis para as problemáticas que as inauguram; é justamente essa possibilidade afirmada que $\mathrm{o}$ acontecimento produz. Ora, se o acontecimento faz surgir essa descontinuidade que provoca uma crise de evidências na história do pensamento, é porque a história permanece aberta a um devir que lhe é própria, a um devir que leva em conta o que é novo, desconhecido, o que é como tal diferença.

Assim, uma análise da história como análise de acontecimentos pretende investigar a história como sendo uma história de problemas, quer reencontrar na história suas descontinuidades. Resgatam-se os jogos de força presentes na formação de um pensamento, bem como as suas linhas de fuga, linhas que são a condição de possibilidade do novo, do diferente. Olhar para os acontecimentos que nos cercam através desse prisma é olhar para os problemas por eles lançados e também olhar para as diferentes formas de solução que diante deles foram definidas (Foucault, 1983/2001). A análise que queremos desenvolver consiste em seguir, primeiramente, as soluções do discurso de Freud para o problema do trauma, e depois, num segundo momento, a formulação do traumático como problema no campo da arqueologia e da genealogia do saber. De uma forma ou de outra, o desafio se mantém o mesmo: realizar uma análise da criação discursiva em psicanálise e de sua disposição possível no pensamento da atualidade.

\section{O TRAUMÁTICO EM PSICANÁLISE: SEDUÇÃO, FANTASMA E FINITUDE}

Logo no início do percurso de Freud, no meio tempo que separa os ditos escritos pré-psicanalíticos dos escritos psicanalíticos propriamente ditos, isto é, nos anos de 1880 e 1890, o plano de conceitos com que se pretendia positivar uma nova teoria do psiquismo supunha uma distinção precisa entre os conteúdos da consciência e os conteúdos separados da consciência (Breuer \& Freud, 1893-1895/1996, pp. 3781). A hipótese freudiana de explicação para a etiologia da histeria tinha como elemento central a suposição de uma experiência traumática, cuja memória estaria associada a certos elementos isolados do psiquismo e deslocados em relação às formas de consciência.

Depois de seu período de pesquisa e de aprendizado junto à Jean-Martin Charcot no Hospital da Salpêtrière em Paris, Freud formulará uma hipótese teórica que irá sustentar pelo menos até meados de 1900. Para o autor, no caso da histeria, o fator etiológico da doença - que estaria ligado não apenas ao momento de causação da histeria, mas também à retomada de sua sintomatologia no quadro na Grande histeria - deveria se dar não no campo corporal da anatomia patológica (Foucault, 1963/1972, pp. 12549), mas no campo significativo da linguagem. É que a experiência em questão na histeria, em geral, experiência de paralisação, seguia um protocolo bastante específico de configuração, uma vez que sem a ocorrência efetiva de uma lesão no nível do corpo, esta deveria se localizar num elemento da linguagem. O que se via na experiência da histeria era a existência de uma experiência de trauma vinculada a uma parte linguageira do corpo, a que Freud chamava de concepção ou sentido popular de corpo (Freud, 1893/1996, pp. 203-213).

Ora, uma tal concepção etiológica e sintomatológica da histeria conduziu Freud a uma outra ideia igualmente necessária, haja vista a configuração dita inconsciente ou mesmo de alteração da consciência no quadro histérico. As palavras ou os signos diretamente afetados na experiência 
de origem do quadro histérico devem estar impedidos de estabelecer associações com as outras representações da consciência; o que implica dizer que, na experiência traumática em questão, o afeto permanecerá retido num conjunto de representações, sem acesso livre ao plano da consciência. O que Freud descobre é que a retomada ou a convocação, por meio da fala ou do toque, da parte corporal específica de concentração dos sintomas rememora o agente causador da doença, e isso sem que o seu conteúdo seja elaborado no plano da consciência e o seu afeto, descarregado no plano motor do corpo. Se a descarga não é plena, nem a lembrança suficiente para a rememoração do traumático, a histérica permanece condenada à repetição de sua história, capaz de operar sozinha a reprodução do trauma e do afeto a ele associado.

Em todo caso, vê-se como é fundamental para Freud, nesse primeiro período de elaboração do trauma, a sustentação de uma distinção efetiva entre conteúdos conscientes e conteúdos separados da consciência, estando o afeto do trauma ligado a estes conteúdos ditos inconscientes. Além disso, observa-se como, no plano da clínica, essa compreensão do trauma impõe a necessidade de uma elaboração do conteúdo e do afeto da experiência traumática, de modo que sua não elaboração implica a repetição hermética e patológica dos sintoma histéricos e a interrupção de qualquer avanço no tratamento. A possibilidade de cura e de intervenção clínica, segundo essa leitura, quer indicar as possibilidades de resgatar a representação do trauma afastada da consciência, de retomar sua experiência pela operação da fala e de reviver o afeto nela contido como se fosse na clínica a primeira vez.

Em todo caso, é a ideia de origem do trauma, a ideia de vinculação entre essa origem e uma representação passível de elaboração, que sustenta a possibilidade de cura e tratamento. Essa ideia, que poderia ser tomada como uma resposta inicial de Freud ao problema do trauma, supõe que na origem existe um trauma que é real, um trauma que é vivido como experiência concreta e material na experiência da subjetividade, um trauma cuja natureza é a da sedução (Freud, 1896/1996, pp.189-215). E essa sedução o que é? Para Freud, trata-se do ato ou da relação que implica a sexualização de um indivíduo passivo mais fraco por parte de um agente mais forte, sendo o primeiro incapaz de elaborar ou de responder a uma tal situação de violência. A formação do trauma se dá em virtude dessa incapacidade, de modo que sua representação estará ligada a um conjunto de signos inconscientes e seu afeto pode ou um não ser convertido num sintoma do corpo. A tentativa de retomar por uma rememoração verbal a cena de sedução é uma oposta de Freud na possibilidade de, no reencontro da cena, produzir uma outra resposta possível à sedução traumática.

O resultado dessa elaboração é a formação freudiana de um conceito fundamental para o discurso e a prática da psicanálise, a saber, o conceito de inconsciente. Esse conceito, dada a natureza da experiência em que ele surge, será regulado por uma gramática traumática da sexualidade. Entendida sob o signo de perverso polimorfa, a sexualidade, em Freud, carregará, por um longo de período, a marca da disjunção e da potencialidade do trauma. De modo que a aposta de Freud é que, por meio de uma técnica da fala e da linguagem, torna-se possível retomar a representação traumática da sedução, elaborando seu conteúdo e liberando o seu afeto na clínica. O nome dessa técnica, em Freud, já na inauguração da psicanálise é o da associação livre.

Pouco antes de 1900, entretanto, Freud abandona a teoria da sedução, diz não acreditar mais em sua neurótica (Masson, 1986, p. 265). Era preciso pensar o trauma não mais a partir da experiência concreta e material da cena, mas a partir da produção de fantasmas. O motivo desse deslocamento permanece emblemático. Poder-se-ia dizer que, em diversos pacientes, não foi possível rememorar com precisão o núcleo da representação traumática, ou que tal núcleo não pôde corresponder a uma situação externa real de acontecimento; tanto faz. O fato é que Freud deixa de acreditar na realidade propriamente dita do trauma, realidade no sentido mais imediato dessa palavra, para afirmar a formação e o desenvolvimento do trauma na fantasia do pensamento. Isso implica dizer que o pensamento freudiano do trauma, sua configuração para pensar o trauma como inconsciente, passa a oscilar entre uma psicologia da imagem ou uma psicologia do imaginário e uma psicologia da palavra ou uma psicologia da linguagem (Foucault, 1954/1994, pp. 69-73). Seja pela imagem, seja pela palavra, a teoria de Freud do psiquismo deve abrir mão da vinculação original das palavras com as coisas em uma representação para pensar essa relação em termos puramente imagéticos ou verbais. $\mathrm{O}$ que quer dizer que as palavras e a coisas passam a funcionar por si mesmas sem a necessidade de uma origem e de uma articulação de representação entre uma e outra.

Essa funcionalidade, a gramática que ela inaugura pelo fantasma com efeito, faz referência em Freud a uma referência central para a formação do desejo e do exercício da sexualidade: o complexo de Édipo (Freud, 1905/1996, p. 179; Freud, 1906/1996, p. 260). É que, quando Freud diz que abandonara a sua neurótica, ele o faz no mesmo movimento em que substitui a realidade do trauma pelo fantasma de Édipo. De modo que é a figura de Édipo, a representação que ela supõe, qual seja, a do assassinato do pai e a do incesto com a mãe, que passa a exercer o papel de regulação e de ordenação das demais representações.

Assim, o trauma do inconsciente torna-se vinculado não a uma realidade de sedução, mas a certa experimentação psíquica de um desejo inaceitável nos tempos modernos. O desejo em Édipo supõe uma moral sexual da civilização, que determina o erotismo a se estender somente a certos objetos e objetivos bem definidos coletivamente (Freud, 1908/1996, pp.172-86). O exercício de uma sexualidade singular e individual torna-se, portanto, submisso às exigências de um universal, que não só reprime o desejo, no sentido mais popular do termo, mas impõe uma medida de 
recalcamento interno capaz de produzir conflito de interesses e transferência de desejos. O objeto sexual desejado deve estar de acordo com os padrões coletivos da civilização. Nessa perspectiva teórica, a sexualidade, para se exercer, deve estar situada entre os pólos da repressão e do exercício livre e desenfreado do desejo. Uma alternativa pensada por Freud surge a partir da noção teórica de sublimação, não obstante essa mesma noção supor a dessexualização do desejo a serviço da civilização.

De qualquer maneira, o que é importante frisar, nessa fase de construção do pensamento de Freud, é o abandono da referência material das coisas e a afirmação da referência fantasmática para pensar o trauma. Toda a sua formação estará submissa a uma nova relação entre as palavras e as imagens no campo do desejo e da sexualidade.

É preciso dizer, no entanto, que permanece em Freud a eleição de um modelo comum de leitura da gramática do desejo. Se Freud se desloca no sentido de abandonar a referência de uma origem do traumático no campo da natureza, a despeito desse deslocamento e dessa colocação dos termos no campo da linguagem e a da imagem, é a referência mesma de uma origem no plano da representação que irá se impor quando ele supor o quadro de Édipo para a regulação do desejo. O resultado dessa eleição é uma psicanálise que funciona sob a base de Édipo e que lê os mecanismos de formação e de produção do desejo a partir dessa referência fundamental (Deleuze \& Guattari, 1972, pp. 32-50, 53, 63-64). Toda a possibilidade de disjunção e de polimorfismo do traumático da sexualidade estará esgotada e restrita à chave interpretativa dos termos de Édipo e dos conflitos edipianos da sexualidade. Torna-se preciso outra conjuntura para positivar o trauma em outros termos.

Ora, se devemos fazer justiça à Freud (Foucault, 1961/1972, p. 360), é porque a partir de 1920 a teoria psicanalítica sofrerá uma mudança radical, ao incluir em seu plano conceitual a categoria moderna da morte. Com o acontecimento da Primeira Guerra, a produção discursiva em psicanálise se defrontará com uma dimensão bastante particular do trauma, que passará a afetar a clínica das neuroses. Trata-se de pensar, sob o pretexto da guerra, as ditas neuroses de guerra e a positivação no plano da experiência dos sonhos de palavras e de imagens que não dão prazer, mas sim dor e desprazer; trata-se de pensar, no interior da produção dos enunciados de Freud, a introdução de uma problemática da finitude, como forma positiva de apresentação do trauma no inconsciente (Freud, 1920/2010).

De fato, em Além do princípio do prazer, Freud está preocupado com essas questões, quer equacionar em sua teoria uma dimensão de sofrimento que ultrapassaria em muito sua até então teoria das neuroses. Existiria um além do princípio do prazer, um além desse fundamento?, interrogase Freud. Com efeito, sua resposta é oscilante em todo o texto: ora apresenta elementos que deveriam ultrapassar o princípio do prazer, isto é, funcionar sob a égide de um outro princípio, ora introduz esses mesmos elementos ainda numa gramática de erotismo que prescreve o prazer como experiência primária, capaz de regular a organização do desejo e dos objetos em torno da satisfação.

Uma leitura que aponta para uma outra forma de relação entre o domínio do inconsciente e a exigência de obtenção do prazer no psiquismo é empreendida por Gilles Deleuze (1967, p.96-99), ao querer pensar a introdução do instinto de morte na obra freudiana como que correspondendo à introdução de um princípio transcendental em psicanálise. É que, com a pergunta sobre um além do prazer, Freud, de fato, caminha de uma busca empírica para a explicação da temática da morte e da destruição para uma busca transcendental na investigação; é que, com a pergunta sobre esse além, o que é introduzido é não uma experiência no campo empírico que excede à busca do prazer, não uma experiência exterior ao campo do prazer, mas sim uma categoria extraexperiencial que se ordena para além da gramática do desejo, a saber, a categoria transcendental da ligação: é preciso ligar o que do campo da experiência está desordenado ou caótico, mesmo que essa tentativa de ligar implique desprazer.

Com efeito, ligar irá se alinhar à toda a temática de Eros no psiquismo, e a força de desligamento, ou seja, a força que reabsorve a temática traumática do inconsciente na nova teoria das pulsões em Freud, pertencerá à atuação de Tânatos. Potência do um e potência do múltiplo, potências transcendentais de ligação e de desligação, as quais, empiricamente dispostas nas experiências subjetivas, introduzem o psiquismo no plano das relações entre prazer e desprazer. Pensar essas duas potências no campo das pulsões é a inovação que traz a contribuição de Freud, de modo que é a temática da morte e sua efetividade moderna na experiência da subjetividade que o jogo de oposição entre pulsão de vida e pulsão de morte reflete na teoria da psicanálise.

Ora, nessa perspectiva, para retomar a história de desenvolvimento do traumático em psicanálise, esse campo do trauma será deslocado do jogo de oposições entre as palavras e as coisas, jogo em que circulava quando afirmado positivamente na realidade da sedução ou na fantasmaticidade das palavras e das coisas, para se afirmar por formas de ligação e de desligamento para além da referência empírica; é essa afirmatividade que permitirá a produção de palavras e de coisas para além da referência de uma representação natural ou fantasmática do um: cena de origem ou fantasma de Édipo. Independente e positivamente, sem qualquer possibilidade de plena apreensão ou de total determinação por um sujeito consciente ou por uma identidade de representação, o inconsciente surge para a psicanálise como modo de encontro do pensamento com a diferença. A finitude a que o traumático se dirige - como indicação da liberdade do múltiplo, que atravessa a subjetividade e que ao atravessá-la impede a organização do desejo por uma gramática da identidade -é esse inconsciente que introduz a psicanálise numa relação com a diferença na arqueologia do saber e na genealogia da modernidade. 


\section{MODERNIDADE EM FORMAÇÃO E FORMAÇÃO DA PSICANÁLISE}

A relação entre psicanálise e modernidade, ou melhor, entre psicanálise e arqueologia e genealogia do pensamento moderno é uma relação complexa. É difícil determinar em que pontos, sob que aspectos, os elementos conceituais de um discurso encontram as regras de formação e a ordem de distribuição das palavras e das coisas (Foucault, 1969). Como não cair em uma determinação unívoca e reduzir planos distintos de operação a um mesmo plano de enunciados e de conceitos, tratando coisas diferentes por palavras semelhantes? Como não transformar aquilo que se propõe como pensamento do inconsciente em um inconsciente do pensamento, já que o próprio pensamento que se supõe falar do inconsciente diz dos acontecimentos determinantes de um modo específico de pensar? Queremos aproximar ambos os campos, produzir pontos comuns sem reconciliar suas diferenças em um mesmo plano de referência. Queremos indicar o que da psicanálise responde a problemas da arqueologia e da genealogia sem confundir a questão que a modernidade coloca às formas de produção de respostas em Freud. De modo que, ao final, nosso objetivo é estabelecer algumas linhas de correlação, cujo saldo seja capaz de produzir a articulação necessária e possível entre uma disciplina discursiva o campo geral de um pensamento.

Quando falamos de modernidade, portanto, estamos falando desse espaço e desse tempo, ou melhor, dessa camada arqueológica e desse momento genealógico, que é condição de possibilidade da produção de discursos. Com efeito, essa camada e esse momento supõem uma separação radical entre as palavras e as coisas. Com a positivação da categoria de história no funcionamento do discurso e do mundo moderno, a relação de semelhança que existia no Renascimento e a relação de representação que existia na chamada idade clássica são rompidas. Doravante as palavras tornam-se autônomas no campo da linguagem e as coisas adquirem uma produção independente das coisas no campo da matéria (Foucault, 1966, pp. 229-233). De modo que é a história que produz uma historicidade interna às palavras e às coisas, haja vista a introdução da categoria de temporalidade que determinará a existência de um devir mais que de uma classificação entre identidade e diferença, própria à taxinomia clássica.

O que os estudos arqueogenealógicos desenvolvidos por Michel Foucault vão mostrar é que essa irrupção da história como acontecimento no campo do pensamento e do discurso moderno foi responsável por produzir uma modificação essencial na base do espaço do saber. Das ditas história natural, análise das riquezas e gramática geral passam a existir as disciplinas da biologia, da economia política e da linguística. Essa transformação no campo do saber está na base mesma das diferentes modificações que ocorrerão nos demais campos de investigação e de produção de saber nas ciências. É essa transformação que irá determinar a produção mais adiante de um discurso denominado de ciências humanas. Mas antes de falarmos desse desdobramento é preciso também dizer que todo o campo empírico das visibilidades também se modificou.

Paralelamente ao aparecimento de uma tríade de saberes: economia política, biologia e linguística, surge no espaço da modernidade três campos empíricos de positivação das palavras e das coisas: a vida, o trabalho e a linguagem (Foucault, 1966, pp. 262-314). A vida, enquanto categoria da biologia, se torna automatizada: todos os estudos de história natural e de biologia devem se concentrar em pensar as operações e classificações dos seres em torno da funcionalidade da vida e da existência. De modo que a vida se torna o grande imperativo de produção discursiva na biologia; sua afirmação escapa à toda tentativa de apreensão e de representação de sua realidade no plano do discurso. No campo da economia e das riquezas, é o trabalho que será positivado; trabalho entendido como modo de operatividade do homem sobre o mundo, modo de produção de bens e de riquezas; de forma que o produto da intervenção humana será avaliado não mais nos termos da oposição entre valor de troca e valor de uso, mas em termos de quantidade de trabalho. É essa quantidade que deverá ocupar a vida dos homens, de modo que individualmente eles serão exigidos na sociedade liberal a exercerem uma boa forma de liberdade. Por fim, é a própria linguagem que surge como modo positivo de afirmação. A história da língua, a história de suas transformações, opera por si na possibilidade de a linguagem se reinventar, e assim fazendo produzir-se ao infinito. Não há qualquer necessidade da elaboração de uma gramática para definir o destino de seu percurso nem o sentido de sua história. De uma semiologia da linguagem na idade clássica passa-se a uma hermenêutica do sentido, hermenêutica definida sempre nos termos próprios dos jogos de verdade produzidos pelos discursos.

Assim, seja pela categoria de vida, pela categoria de trabalho, ou ainda pela categoria de linguagem, a realidade das palavras e das coisas é positivada, ultrapassando as determinações da representação e ocasionando o fim de um discurso da identidade, característico do pensamento clássico. Na modernidade, o pensamento e o discurso tornam-se reféns dessa realidade positiva que os ultrapassa e os limita, tornam-se determinados a pensar esse impensado do pensamento - o que indica necessariamente sua finitude enquanto projeto e sua impossibilidade de construção nos termos de um progresso ou avanço do conhecimento. Pensamento do impensado, finitude da existência é sob a égide desses dois programas que a categoria de história acontece na história moderna da arqueologia e da genealogia, de acordo com Foucault (1966, pp. 314-355). Que lugar a psicanálise tem nesse panorama?, é a pergunta que queremos fazer, de modo que para respondê-la permaneceremos nas pistas de Foucault para depois retomarmos a reflexão sobre o traumático em Freud. 
A psicanálise, enquanto discurso e enquanto prática, positiva em seu interior diferentes programas da arqueologia e da genealogia. Com efeito, na psicanálise, no interior dela, de sua formação e de seu percurso de desenvolvimento, fantasmas de um pensamento da semelhança, de um pensamento da representação e de um pensamento da história se fazem existir positivamente. É que quando Freud define o inconsciente como um traumático material, cuja representação verbal no psiquismo reproduz a materialidade das coisas, ele é renascentista, pela semelhança das palavras com as coisas; é que quando Freud define o inconsciente como um fantasma de palavras e de imagens, cujo funcionamento se dá sem referências as coisas, mas sob a representação central de Édipo, ele é inteiramente clássico; isso porque Édipo passa a representar a ordenação gramatical do desejo em torno de uma identidade da representação; por fim, é que quando Freud define o inconsciente como uma pulsão, dividindo esta em torno da vida e da morte, ele é moderno: as referências principais de Freud são o impensado do pensamento e a finitude da existência; trata-se da positivação de toda uma fenomenologia da morte, o que inclui as possibilidades de criação e de destruição de si e dos outros.

Perpassando por esses três momentos de produção de conceitos em Freud, as categorias da semelhança, da representação e da história fazem falar toda uma dimensão acontecimental de seu pensamento. Nesse sentido, elas incluem o discurso psicanalítico num vínculo muito estreito com os acontecimentos determinantes da história do pensamento moderno. Quando Foucault vai se referir à psicanálise e à etnologia como referências discursivas centrais para se pensar a modernidade, sua reflexão se encaminhará no sentido de que - para além do objeto dessas ciências, isto é, do inconsciente do psiquismo, no caso da psicanálise, e das estruturas inconscientes de parentesco, no caso da antropologia - essas ciências dão vazão aos acontecimentos a priori da modernidade, fazem falar da historicidade introduzida no coração das palavras e das coisas e da positivação da categoria de finitude na irrupção histórica de um pensamento do homem (Foucault, 1966, pp.385-398). De modo que o que permanece traumático nessa articulação, nessa articulação em que a psicanálise e a etnologia encontram a arqueologia e a genealogia, é o ponto de irrupção e de descontinuidade dessas disciplinas em relação ao campo das ciências humanas. Torna-se preciso distinguir os acontecimentos da história e da finitude em relação à positivação dessa figura idêntica do que seja o homem no espaço moderno do saber e do poder.

\section{A QUESTÃO DO HOMEM E O TRAUMA DO PENSAMENTO}

Com a positivação da vida, do trabalho e da linguagem, um outro registro empírico aparece no espaço do saber. Um registro antes impensado no espaço da representação, uma vez que o próprio espaço que supunha sua presença não era colocado em questão. Se a representação assegurava a passagem segura entre o ser e o pensamento, haja vista o cogito de Descartes, o ser ele mesmo não podia ser pensado; estava imerso no pensamento, sendo ele refletido e referido de maneira imediata, ou seja, sem qualquer mediação. Quando a história produz um afastamento entre ser e pensamento, é preciso que este último reencontre aquele no campo do saber; aquele se torna positivado como acontecimento, de modo que surge o homem e o pensamento que o acompanha, o pensamento que surge para pensar o homem: as ciências do homem (Foucault, 1966, pp. 355-398).

De fato, o homem surge como positividade no campo empírico, ao lado da vida, da linguagem e do trabalho, e as ciências humanas, igualmente, no campo do saber, ao lado das ciências da biologia, da economia política e da linguística. A questão é que, paradoxalmente, se o homem $\mathrm{e}$ as ciências humanas se produzem num momento em que a história atinge as palavras e as coisas e que produz uma separação entre elas, eles são elevados por uma antropologia silenciosa à posição de figura transcendental. Por meio dessa figura, figura metafísica do homem, que as ciências humanas pretendem representar o campo da vida, do trabalho e da linguagem, submetendo esses diferentes domínios do saber a um pensamento universal do sujeito e da identidade de representação entre sujeito e objeto (Foucault, 1961/1972, p. 541; Foucault, 1961/2007, pp. 122-124; Foucault, 1966, pp. 351-354)

De modo que é contra a necessidade dessa resposta dada pelas ciências do homem que o empreendimento de Michel Foucault, ao apontar o caráter de contingência dos acontecimentos, vai se colocar. Trata-se de retomar os problemas da história e da finitude, problemas colocados como acontecimentos diferenciais da história, e entender o homem apenas como uma das respostas possíveis para essa questão. $\mathrm{O}$ homem não é primeiro na determinação da realidade moderna, nem ocupa o lugar de origem e de destino desse pensamento. Longe de se constituir como uma figura fixa e permanente no espaço do saber, é uma figura passageira e instável. Assim como se formou e se constituiu, de um momento para outro, pode em breve desaparecer - se ainda não desapareceu.

Quando a psicanálise quer retomar a centralidade da consciência no modelo de inconsciente traumático, quando quer ordenar a sexualidade neurótica a partir de Édipo e, ainda, quando quer minimizar a atuação de Tânatos e do trabalho da finitude na produção das subjetividades, ela se aproxima de um modelo de representação do homem. Trata-se um pensamento que mantém no horizonte central 
de sua atuação a identidade do sujeito e a representação dessa identidade por uma hermenêutica fechada da vida, do trabalho e da linguagem. É preciso, no entanto, que a psicanálise mantenha no coração de sua prática a referência aos acontecimentos da modernidade: impensado do inconsciente e finitude da pulsão. Somente nesses termos, sua resposta à questão do trauma permanece ligada ao princípio de sua formação como problema. Como um pensamento do acontecimento, longe de se produzir como imagem do mesmo, reproduz o lugar do que está fora do pensamento, do que no pensamento se manifesta como outro (Deleuze, 1968, pp.169-217; Foucault, 1970/1994, pp. 83, 89-90, 97-99).
Nessa perspectiva, o traumático como problema não se introduz no campo de discurso e de prática da psicanálise necessariamente como um impasse a ser superado ou como um momento de falha da teoria ou da técnica psicanalítica. Não se trata da resistência de uma realidade, nem da indeterminação própria de um real. Ao contrário disso, o trauma se torna figura e expressão de um pensamento comprometido com a diferença, com a sua plena determinação como problema. Esse pensamento só pode ser formado por uma relação estreita com os acontecimentos de sua condição e com os problemas lançados por esses mesmos acontecimentos.

\section{REFERÊNCIAS}

Breuer, J., \& Freud, S. (1996) Estudos sobre histeria (C. M. Oiticica \& V. Ribeiro, Trad.). Em S. Freud, Obras psicológicas completas de Sigmund Freud: Edição standard brasileira (Vol. 2, pp. 39-316). Rio de Janeiro: Imago. (Original publicado em 1893-1895)

Deleuze, G. (1967). Présentation de Sacher-Masoch: Le froid et le cruel. Paris: Minuit.

Deleuze, G. (1968). Différence et répétition. Paris: PUF.

Deleuze, G., \& Guattari, F. (1972). Capitalisme et schizophrénie 1: L'anti-Oedipe. Paris: Minuit.

Foucault, M. (1966). Les mots et les choses: Une archéologie des sciences humaines. Paris: Gallimard.

Foucault, M. (1969). L'archéologie du savoir. Paris: Gallimard.

Foucault, M. (1972). Histoire de la folie à l'âge classique. Paris: Gallimard. (Original publicado em 1961)

Foucault, M. (1972) Naissance de la clinique: Une archéologie du regard médical. Paris: PUF. (Original publicado em 1963)

Foucault, M. (1994). Introduction. Em M. Foucault, Dits et écrits, 1954-1988 (Vol. 1, pp. 65-119). Paris: Gallimard. (Original publicado em 1954)

Foucault, M. (1994). Theatrum philosophicum. Em M. Foucault, Dits et écrits, 1954-1988 (Vol. 2, pp. 75-99). Paris: Gallimard. (Original publicado em 1970)

Foucault, M. (1994). Nietzsche, la généalogie, l'histoire. Em M. Foucault, Dits et écrits, 1954-1988(Vol. 2, pp.136-156). Paris: Gallimard. (Original publicado em 1971)

Foucault, M. (1994). Table ronde du 20 mai 1978. Em M. Foucault, Dits et écrits, 1954-1988 (Vol. 4, pp. 20-34). Paris: Gallimard. (Original publicado em 1980)

Foucault, M. (1994). Qu'est-ce que les Lumières?. Em M. Foucault, Dits et écrits, 1954-1988 (Vol. 4, pp. 679-688). Paris: Gallimard. (Original publicado em 1984a)

Foucault, M. (1994). Polémique, politique et problématisations. Em M. Foucault, Dits et écrits, 1954-1988 (Vol. 4, pp. 591-598). Paris: Gallimard. (Original publicado em 1984b)
Foucault, M. (2001). Discourse and truth: The problematization of parrhesia (six lectures given by Michel Foucault at Berkeley). Em J. Pearson (Ed.), Fearless speech. Los Angeles: Semiotext(e). (Original publicado em 1983)

Foucault, M. (2007). Introduction to Kant's Anthropology (R. Nigro \& K. Briggs, Trad.). Los Angeles: Semiotext(e). (Original publicado em 1961)

Freud, S. (1996). Algumas considerações para um estudo comparativo das paralisias motoras orgânicas e histéricas (J. L. Meurer, Trad.). Em S. Freud, Obras psicológicas completas de Sigmund Freud: Edição standard brasileira (Vol. 1, pp. 203-218). Rio de Janeiro: Imago. (Original publicado em 1893)

Freud, S. (1996). A etiologia da histeria (M. Salomão, Trad.). Em S. Freud, Obras psicológicas completas de Sigmund Freud: Edição standard brasileira (Vol. 3, pp. 187-215). Rio de Janeiro: Imago. (Original publicado em 1896)

Freud, S. (1996). Três ensaios sobre a teoria da sexualidade (V. Ribeiro, Trad.). Em S. Freud, Obras psicológicas completas de Sigmund Freud: Edição standard brasileira (Vol. 7, pp. 119-232). Rio de Janeiro: Imago. (Original publicado em 1905)

Freud, S. (1996). Minhas teses sobre o papel da sexualidade na etiologia das neuroses (V. Ribeiro, Trad.). Em S. Freud, Obras psicológicas completas de Sigmund Freud: Edição standard brasileira (Vol. 7, pp. 255-266). Rio de Janeiro: Imago. (Original publicado em 1906)

Freud, S. (1996). Moral sexual 'civilizada' e doença nervosa moderna (M. A. M. Rego, Trad.). Em S. Freud, Obras psicológicas completas de Sigmund Freud: Edição standard brasileira (Vol. 9, pp. 169-188). Rio de Janeiro: Imago. (Original publicado em 1908)

Freud, S. (2010) Além do princípio do prazer (P. C. de Souza, Trad.). Em S. Freud, Obras completas (Vol. 14, pp. 161-239). São Paulo: Companhia das Letras. (Original publicado em 1920)

Masson, J. M. (1986) A correspondência completa de Sigmund Freud para Wilhelm Fliess, $1887-1904$ (V. Ribeiro, Trad.). Rio de janeiro: Imago. 